\title{
Eifect of Weight Reduction on Cardiovascular Risk Factors and CD34-positive Cells in Circulation
}

\author{
Nina A Mikirova ${ }^{\bowtie}$, Joseph J Casciari, Ronald E Hunninghake, Margaret M Beezley \\ The Riordan Clinic, 3100 N, Hillside, Wichita, KS, USA
}

Corresponding author: Nina A Mikirova, 3100 N Hillside, Wichita, KS, 67219. Phone: 316-6823100 ext 253; Fax: 316-6825054, email: nmikirova@riordanclinic.org

(ㅇ Ivyspring International Publisher. This is an open-access article distributed under the terms of the Creative Commons License (http://creativecommons.org/ licenses/by-nc-nd/3.0/). Reproduction is permitted for personal, noncommercial use, provided that the article is in whole, unmodified, and properly cited.

Received: 2011.07.01; Accepted: 2011.07.20; Published: 2011.08.01

\begin{abstract}
Being overweight or obese is associated with an increased risk for the development of non-insulin-dependent diabetes mellitus, hypertension, and cardiovascular disease. Dyslipidemia of obesity is characterized by elevated fasting triglycerides and decreased high-density lipoprotein-cholesterol concentrations. Endothelial damage and dysfunction is considered to be a major underlying mechanism for the elevated cardiovascular risk associated with increased adiposity. Alterations in endothelial cells and stem/endothelial progenitor cell function associated with overweight and obesity predispose to atherosclerosis and thrombosis.

In our study, we analyzed the effect of a low calorie diet in combination with oral supplementation by vitamins, minerals, probiotics and human chorionic gonadotropin (hCG, 125-180 IUs) on the body composition, lipid profile and CD34-positive cells in circulation.

During this dieting program, the following parameters were assessed weekly for all participants: fat free mass, body fat, BMI, extracellular/intracellular water, total body water and basal metabolic rate. For part of participants blood chemistry parameters and circulating CD34-positive cells were determined before and after dieting.

The data indicated that the treatments not only reduced body fat mass and total mass but also improved the lipid profile. The changes in body composition correlated with the level of lipoproteins responsible for the increased cardiovascular risk factors. These changes in body composition and lipid profile parameters coincided with the improvement of circulatory progenitor cell numbers.

As the result of our study, we concluded that the improvement of body composition affects the number of stem/progenitor cells in circulation.
\end{abstract}

Key words: weight reduction, body composition, cardiovascular risk factors, lipid profile, progenitor cells.

\section{Introduction}

Living in an environment characterized by calorie-rich foods and low physical activity, over two thirds of Americans are overweight [1]. This is a major public health problem, as obesity predisposes to a variety of age-related inflammatory diseases, includ- ing insulin resistance, type 2 diabetes, atherosclerosis and its complications, fatty liver diseases, osteoarthritis, rheumatoid arthritis, and cancer [2-4]. Clinical studies have identified a relationship between increased body weight and cardiovascular disease in- 
cluding coronary atherosclerosis, congestive heart failure, arrhythmias, and stroke [5-11].

In addition to established cardiovascular risk factors, systemic inflammation, increased oxidative stress, and altered hemodynamics associated with excess weight may directly contribute to endothelial injury and dysfunction [12]. Progenitor cells, which are released from the bone marrow are sensitive to oxidative stress [13-16]. Circulating endothelial progenitor cell (EPC) numbers have been found to be lower in obese subjects compared to overweight or normal weight adults, and the colony-forming capacity of these cells is blunted $[17,18]$. Alterations in endothelial cells and EPC function associated with obesity precede atherosclerosis and thrombosis [19-21]. Moreover, EPCs expanded from the obese subjects possessed reduced adhesive, migratory, and angiogenic capacity [22] and fail to respond to vascular endothelial growth factor. Mice treated with obese EPCs exhibited reduced EPC homing in ischemic hind limbs in vivo.

Etiology of obesity is complex, involving interrelated biochemical, neurological physiological, genetic, environmental, cultural and psychological factors. Adipose tissue can be considered as an endocrine organ that mediates biological effects on the metabolism and inflammation, contributing to the maintenance of energy homeostasis and the pathogenesis of obesity-related metabolic and inflammatory complications [4]. Endothelial damage and dysfunction is considered to be a major underlying mechanism for the heightened cardiovascular burden that occurs with increased adiposity.

The goal of our study was to examine how cardiovascular risk factors and circulating CD34-positive cell numbers correlate when overweight subjects attempt to lose weight through calorie restriction. The particular weight loss regimen we examined consisted of severe calorie restriction along with vitamin supplements and administration of human chorionic gonadotropin (hCG), a hormone that encourages metabolic utilization of visceral fat reserves [23-26].

\section{Materials and Methods}

\section{Weight Loss Protocol}

Our study consisted of fifty three participants, eighty percent of which were women, with ages ranging from 26 to 63 . The starting body mass index of these subjects ranged from 30 to 67 , while their body fat percentage ranged from $15 \%$ to $48 \%$ when they began treatment. All subjects gave written informed consent (as per Helsinki Declaration guidelines) and underwent the dietary program with the oversight of their primary care physician. Although, the program mainly aimed at overweight and obese people, it was open to anyone interested.

The weight loss program consisted of a 500 calorie per day dietary restriction in combination with the following:

1. Daily sublingual treatments by vitamin $B 12$ (1,000 $\mu$ g per day).

2. Oral supplements consisting of the following nutrients: $250 \mathrm{mg}$ tyrosine, $2 \mathrm{mg} \beta$-glucan, $200 \mu \mathrm{g}$ selenium, $1 \mathrm{mg}$ folic acid, $5 \mathrm{mg}$ iodine, $7.5 \mathrm{mg}$ potassium iodide, $600 \mathrm{mg}$ magnesium, $5 \mathrm{~g}$ vitamin D3, $60 \mathrm{mg}$ coenzyme Q10, $150 \mathrm{mg}$ lipoic acid, $340 \mathrm{mg}$ acetyl-l-carnitine, $100 \mathrm{mg}$ vitamin B complex, and a probiotic ( 2 billion CFU acidophilus with 2 billion CFU bifidus and $109 \mathrm{mg}$ FOS).

3. Daily treatments of hCG nasal spray, at doses of 125 - 180 IU.

The very low calorie diet can be summarized as follows: breakfast consisted of coffee/tea with no sugar or one fruit serving, while lunch and dinner each consisted of $3.5 \mathrm{oz}$ lean protein, a vegetable serving, bread serving, and a fruit serving. The program schedule was as follows: patients took supplements, B12, and hCG for two days prior to beginning a 36-day very low calorie diet. This was followed by a 35 day maintenance period during which calorie intake was gradually raised while restricting sugar and starch intake (at this point, hCG treatment stopped).

Subjects were supervised by a physician with weekly health evaluations. The following parameters were assessed weekly: body composition, including fat free mass (FFM), body fat (BF), total body water (TBW), intracellular/extracellular water, basal metabolic rate and body mass index (BMI). Blood chemistry parameters, including glucose, cholesterols, triglycerides and circulating CD34-positive cells were measured for nine subjects at the beginning and at the end of the study. Eight of the nine subjects who volunteered for blood work were female: they ranged in age from thirty to sixty-five years old. The lone male was forty years old.

Assay methods are described below.

\section{Body composition}

Body composition was measured by bioelectrical impedance analysis (BIA). The BIA is a non-invasive method for measuring body composition through reactance and resistance, the two components of impedance. Bioelectrical impedance analysis was performed by IMP DF50 (Company ImpediMed Limited). The fat-free mass, body fat, basal metabolic rate, total body water, extracellular water, intracellular 
water and body mass index were determined for each participant before dieting intervention and each six days following intervention.

\section{Assay of lipid profile}

A fasting serum was used for measurements of the lipid profile (total cholesterol, high-density lipoprotein cholesterol (HDL), low-density lipoproteins (LDL), triglycerides, very low-density lipoproteins (VLDV)) and glucose, by established clinical laboratory tests. Cholesterol, HDL cholesterol, and triglycerides were quantified by an auto-analyzer by an enzymatic method by using commercially available reagents (Genzyme Diagnostics). LDL cholesterol (in fasting samples) was determined by calculation.

\section{CD34-positive cell measurements}

The analysis of the CD34 positive cells was performed by adopting the gating strategy defined by the International Society of Haematotherapy and Graft Engineering (ISHAGE) guidelines [27]. The method of the selection of stem/progenitor cells consisted from several criteria. Cells were selected that expressed CD34+ antigen, did not express CD45 antigen and exhibited low side-angle light scatter characteristics of blasts cells. This subpopulation was defined as of endothelial progenitor cells. Our decision to considered CD34 positive/CD45 negative circulating cells as "circulating EPCs" was based on the work [28], in which blood-derived cells from which endothelial cells in culture were developed were described as cells expressing CD34 antigen. It has been hypothesized that endothelial progenitor cells and hematopoietic progenitor cells have common precursor, the hemangioblast and both may be subsets of bone marrow-derived progenitor cells expressing CD34. Moreover, recent studies demonstrate that CD34+ cells not expressing leukocyte antigen (CD45-) form endothelial colony-forming units and those expressing CD45 demonstrate hematopoietic properties [29].

Specific cell surface staining was accomplished by incubating duplicate samples of a biological specimen (separated white blood cells) with two color CD45-FITC/CD34-PE reagents (Stem kit reagents, Beckman Coulter). In an additional test, the samples were stained with CD45-FITC/IsoClonic Control-PE reagent to check the non-specific binding of the CD34-PE monoclonal antibody.

\section{Statistical analysis}

All data were analyzed by Systat software (Systat Inc) and KaleidaGraph software. Variables were presented as mean values $\pm S D$. Statistical analysis was done by linear regression model and paired non-parametrical test. Statistical significance was accepted if the null hypothesis could be rejected at $\mathrm{p}<0.05$.

\section{Results}

The distributions of mass loss and fat mass loss by all subjects during the diet are shown in Figure 1.

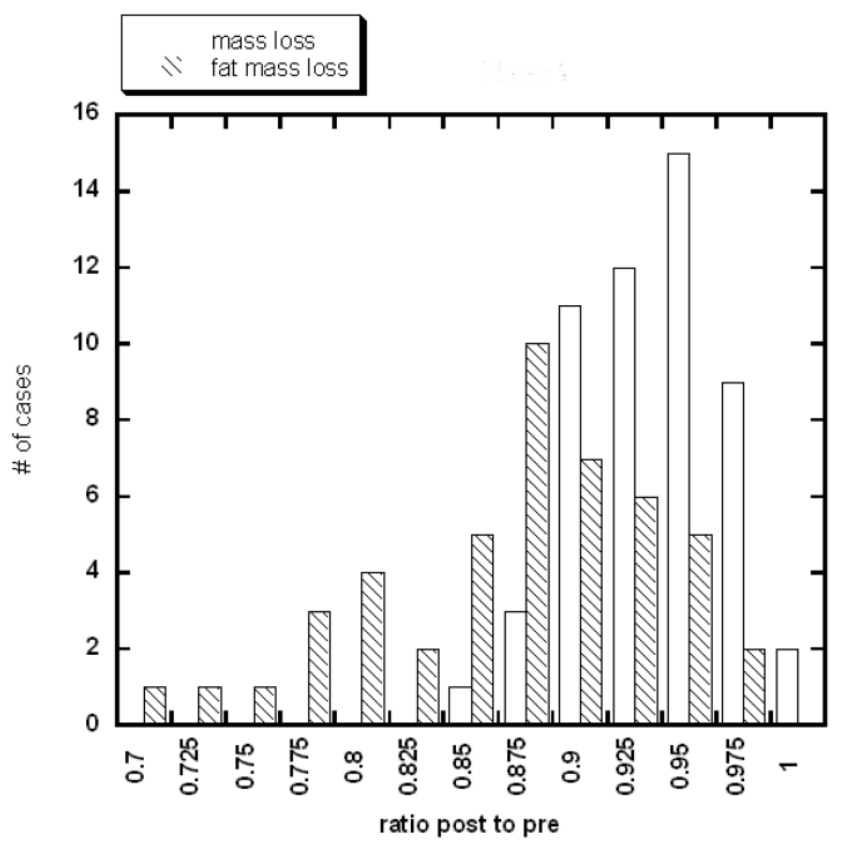

Figure 1. Distribution of the weight reduction and fat mass loss in all subjects participated in 36 days of the dieting program.

Subjects lost between 2.5 and $17.2 \mathrm{~kg}$ during the study, with the most weight loss occurring in subjects who started out the heaviest. All subjects achieved a decrease in body mass index during the study. The average BMI for participants at the start of the study was $34.0 \pm 7.2(\mathrm{SD})$, while that after the study was 28.5 \pm 6.7 (SD). Using a paired Student's t-test, the difference is highly significant $(p=0.0004)$. This indicates that weight loss and changes in body composition did occur during the time course of the study.

The weight reductions during the hypo-caloric diet and maintenance period for several patients are presented in Figure 2.

Changes in body composition parameters are summarized in Table 1.

These percentages did not vary systematically with the initial mass of the subjects. The decrease in body fat was substantial, and in most cases larger than the corresponding loss in lean mass. According to our data, the average percentage loss of lean mass was $5.7 \pm 4.7$ and the average change in body fat was 
12.4 \pm 8.7 . The percentage loss in body fat among the most subjects was significantly larger $(p=0.04)$ than the percentage loss in lean mass, suggesting an improvement in body composition.

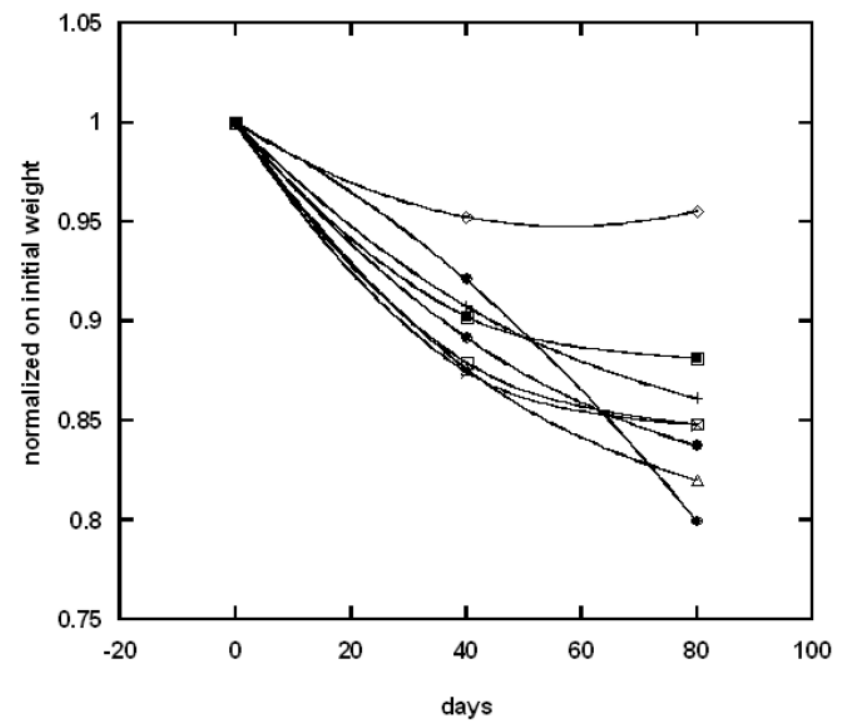

Figure 2. Examples of the effect of dieting and maintenance periods on the weight loss for several participants.

Table 1. Percent of decrease in total mass, fat free mass, intracellular/extracellular fluids and basal metabolic rate in subjects at the end of the study.

\begin{tabular}{llll}
\hline Parameter & $\begin{array}{l}\text { Mean } \\
\pm S D\end{array}$ & $\begin{array}{l}\text { Minimum } \\
\text { value }\end{array}$ & $\begin{array}{l}\text { Maximum } \\
\text { value }\end{array}$ \\
\hline Weight kg & $8.1 \pm 3.3$ & 1.8 & 16.9 \\
Total Body Water Liter & $5.7 \pm 4.7$ & -3.2 & 16.1 \\
Total Body Water \% & $-2.6 \pm 4.1$ & -13.4 & 8.8 \\
Intracellular Fluid Liter & $5.7 \pm 6.3$ & -11.3 & 15.7 \\
Intracellular Fluid \% & $0.0 \pm 3.0$ & -9.2 & 4.7 \\
$\begin{array}{l}\text { Extracellular Fluid } \\
\text { Liter }\end{array}$ & $5.8 \pm 4.6$ & -4.0 & 18.0 \\
Extracellular Fluid \% & $0.0 \pm 3.1$ & -5.1 & 9.2 \\
Fat Free Mass kg & $5.7 \pm 4.7$ & -3.4 & 16.1 \\
Fat Free Mass \% & $-2.6 \pm 4.2$ & -13.6 & 8.8 \\
Fat Mass kg & $12.4 \pm 8.7$ & -8.4 & 31.2 \\
Fat Mass \% & $4.7 \pm 8.3$ & -11.2 & 26.7 \\
$\begin{array}{l}\text { Basal Metabolic Rate } \\
\text { Mi }\end{array}$ & $3.9 \pm 2.0$ & 0.0 & 10.1 \\
$\begin{array}{l}\text { Basal Metabolic Rate } \\
\text { CAL }\end{array}$ & $4.1 \pm 2.0$ & 0.9 & 10.1 \\
Body Mass Index & $8.1 \pm 2.0$ & 2.0 & 16.9 \\
\hline
\end{tabular}

The treated subjects showed a decrease in their body mass index in an average of $8.1 \% \pm 2.0 \%$.

Changes in total body water had inverse correlation with changes in fat mass $(\mathrm{r}=0.86)$ and positive correlation with an increase in fat free mass $(\mathrm{r}=0.78)$. The level of intracellular water (ICW) correlated with fat mass and fat free mass changes during dieting. Intracellular water levels showed linear relation with fat free mass $(\mathrm{r}=0.9)$ and an inverse relation with fat mass $(r=0.6)$. As intracellular fluid decreases due to different pathological conditions, the increase in intracellular water suggests improvement in cell health and nutritional status.

Basal metabolic rate decreased slightly in subjects during their treatment $(4.1 \% \pm 2.0 \%)$. The percentage of the decrease in BMR correlated with the percentage of weight loss. The decreasing of BMR is not desirable for dieters; however, the BMR decrease seen in our study is modest.

Statistically significant decreases in serum cholesterol levels were observed during the treatment. Lipid profile data are summarized in Table 2.

Table 2: Averaged blood chemistry parameters before and after the diet regiment are given. $\dagger$ indicates significant difference between "Pre" and "Post" $(p<0.05$ using paired Student's t-test).

\begin{tabular}{lll}
\hline Lipid profile & Pre & Post \\
\hline Glucose $(\mathrm{mg} / \mathrm{dL})$ & $91 \pm 12$ & $89 \pm 7$ \\
Cholesterol (mg/dL) & $206 \pm 36$ & $177 \pm 24 \dagger$ \\
Triglyceride (mg/dL) & $119 \pm 57$ & $97 \pm 36$ \\
HDL Cholesterol (mg/dL) & $52 \pm 13$ & $52 \pm 10$ \\
VLDL (mg/dL) & $24 \pm 11$ & $19 \pm 7$ \\
LDL(mg/dL) & $130 \pm 29$ & $106 \pm 21 \dagger$ \\
Cholesterol / HDL & $4.2 \pm 1.2$ & $3.5 \pm 0.8 \dagger$ \\
LDL / HDL & $2.7 \pm 0.9$ & $2.1 \pm 0.7 \dagger$ \\
\hline
\end{tabular}

While glucose levels, triglycerides, very low density lipoproteins (VLDL), and high density lipoproteins (HDL) were not affected, subjects saw significant decreases in total cholesterol, low density lipoprotein (LDL), and overall in ratios of cholesterol and LDL to HDL. These variables are considered markers of cardiovascular disease. HDL protects arteries by transporting cholesterol away, while LDL can be deposited on arterial walls and clog arteries. Changes in the level of cholesterol and LDL for all participants are shown in Figures 3, 4.

For total cholesterol, the upper limit of the normal range is $200 \mathrm{mg} / \mathrm{dL}$. Five of the subjects started the study above this threshold. All of these participants experienced cholesterol decreases during the 
diet treatment, with two returning completely to the normal range. The upper limit of the normal range for LDL is $100 \mathrm{mg} / \mathrm{dL}$. Eight of the nine subjects started with above normal LDL, with three of them returning to normal levels during the treatment. Similar trends were seen with the cholesterol/HDL ratio (upper limit of normal being 5.0) and LDL/HDL (upper limit of normal being 3.6).

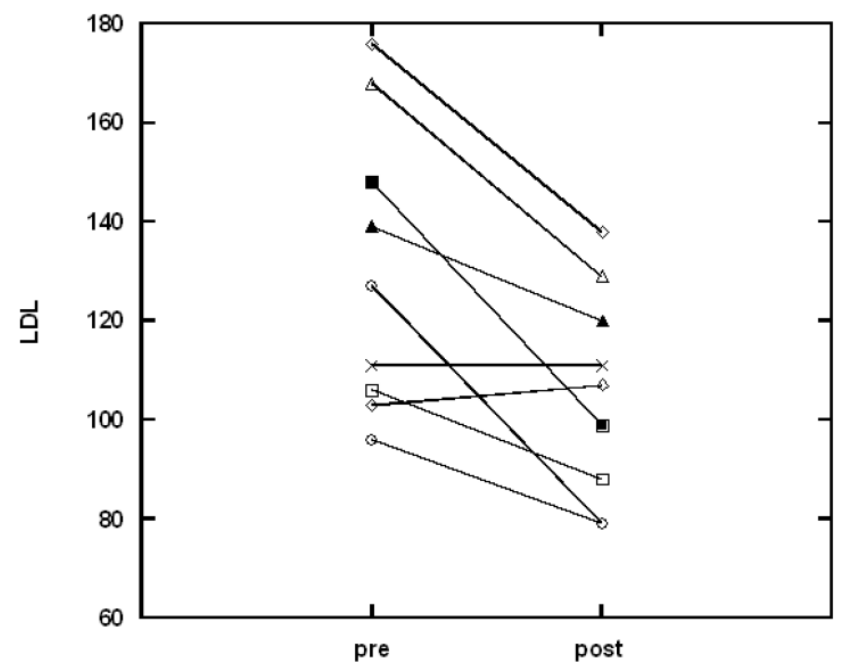

Figure 3. The effect of the dieting program on the level of LDL in plasma.

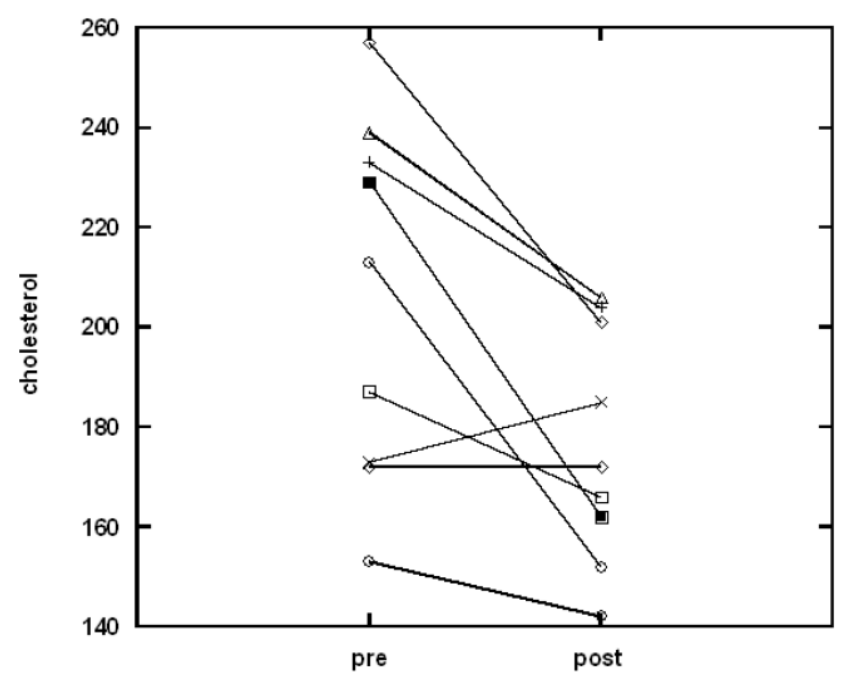

Figure 4. The effect of the dieting program on the level of cholesterol in plasma.

Regression analysis was conducted between body composition parameters and lipid profile parameters. The mass of body fat $(\mathrm{BF})$ correlated strongly with the LDL to HDL ratio $(r=0.7)$, the cholesterol to HDL ratio $(r=0.68)$ and inversely with HDL $(\mathrm{r}=0.43)$.
Overall, these data indicated that the combination of a low calorie diet with hCG treatments reduced body fat as well as risk factors associated with cardiovascular disease.

Circulating CD34+ cells in peripheral blood, as a percentage of total leukocyte counts, were determined before and after the study. Weight loss was accompanied by a significant improvement in the number of circulating progenitor cells $(p<0.01)$. On average, the enhancement of progenitor cell numbers was roughly seventy percent. Figure 5 shows how CD34+ cell levels changed for each subject from the start to the end of the weight loss program.

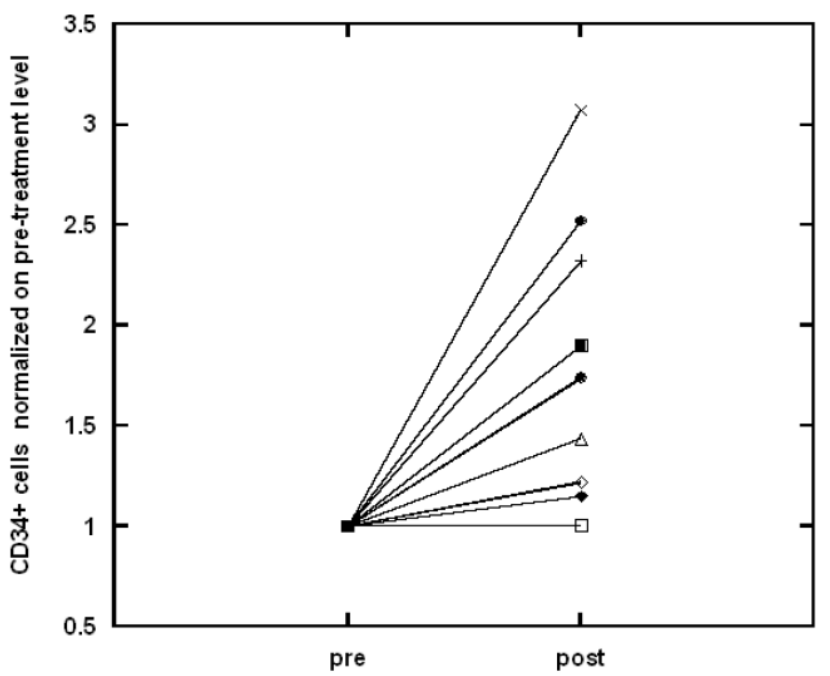

Figure 5. The improvement of CD34 positive cell number after diet.

Figure 6 shows the correlation between circulating CD34+ cell number (given here as the ratio of the percentage of cells after the diet to the percentage of cells before the diet) and the percentage of body fat lost by each subject during the study.

A correlation also exists between CD34+ cells and the proportion of fat free mass $(r=0.80)$ for each subject. The changes in body fat, and the changes in lipid profile parameters, coincide with improvements in circulatory progenitor cell numbers.

To rule out the possibility that changing numbers of circulating CD34+ cells were simply part of an overall change in circulating white blood cells, we ran complete blood counts before and after treatment on the nine subjects who consented to blood work. Changes in blood cell counts with treatment varied among the nine subjects, with five experiencing overall decreases (the maximum downward change was thirty percent). All subjects showed a decrease in 
lymphocyte counts (the decrease ranged from eight to thirty-five percent).

The normalization of CD34-positive cell numbers to total peripheral blood mononuclear cell numbers, demonstrated that the numbers of CD34-positive cells per micro liter increase by an average of forty percent.

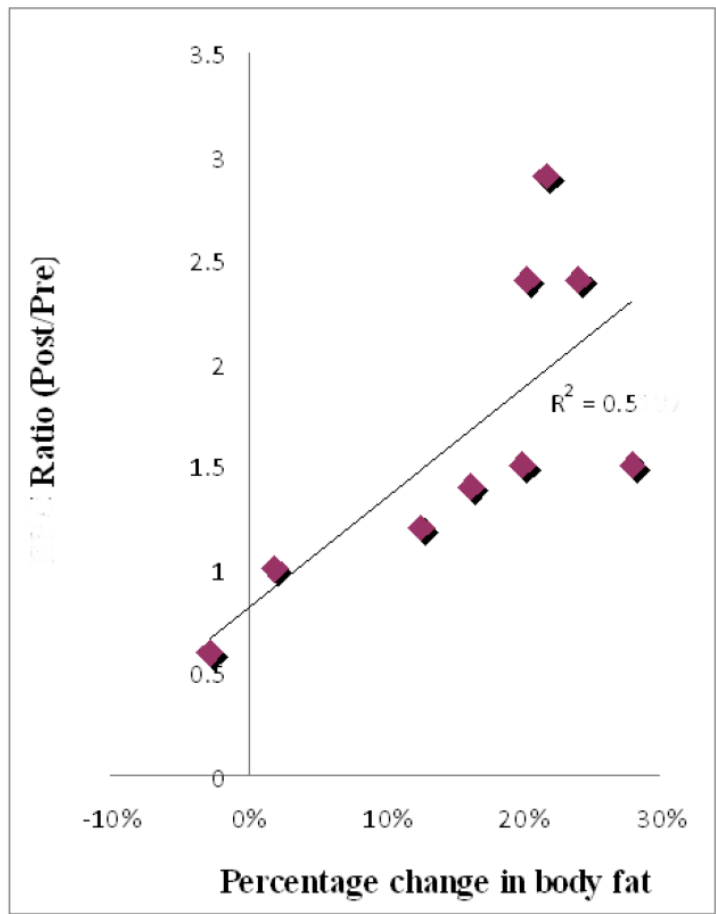

Figure 6. The ratio of CD34+ cells post diet to pre-diet as a function of percentage of body fat lost during the diet.

\section{Discussion}

Obesity is frequently associated with traditional cardiovascular risk factors such as type 2 diabetes, hypertension, dyslipidemia, altered coagulation/fibrinolysis, and the other components of the metabolic syndrome [30]. All these abnormalities create a state of constant and progressive damage to the vascular wall, manifested by a low-grade progressive inflammatory process and endothelial dysfunction $[31,32]$.

The endothelial cell damages due to dyslipidemia and proinflammatory cytokines have been demonstrated in studies [33, 34]. Increased levels of triglycerides and lipoproteins in obese or overweight subjects correlate with impairment of endothelial function [35, 36]. Endothelial cell damage due to dyslipidemia plays a critical role in the development and progression of atherosclerosis $[37,38]$.
Given the role of endothelial cell damage in obesity, our attention was turned to progenitor cells (CD34+/CD45- cells). These cells are thought to be early precursors of endothelial progenitor cells and function to replenish aging as well as damaged endothelial cells that line blood vessels. There is strong evidence of the role of circulating endothelial progenitor cells, including populations of CD34 positive cells presented in peripheral blood, in the maintenance of the vasculature and neovascularization [39, 40]. In several studies, the number of circulating EPCs and their migratory activity have been reported to be reduced in patients with risk factor for coronary artery disease and negatively correlated with the Framingham cardiovascular risk score [41-43]. Therefore, increasing the number of CD34-positive cells during treatment may provide an indicator of improvement of vascular health.

In our study, we analyzed the effect of weight loss on the improvement of lipid profile in plasma and the increase of the level of CD34+/CD45- cells in circulation.

The data from our study demonstrated that a combination of a very low calorie diet with hCG treatments, and supplements, decreases overall mass and body fat while improving lipid profiles. These benefits are accompanied by increases in circulating CD34+ cell numbers.

The weight loss protocol, which we used in our study, was developed in the 1950s [23, 24]. Several studies have been done to examine the efficacy of hCG in treating obesity, with mixed results $[44,45]$. The main question has been whether the addition of hCG to a very low calorie diet enhances weight loss compared to dieting alone. While most studies report weight loss due to dieting, they disagree as to whether factors such as weight reduction, body proportion, and patient reported hunger level are affected by adding hCG to the diet. The issue is complicated by the fact that few of these studies were double-blind and placebo controlled. The experimental design used in the study [46] showed that the combination of the 500 calorie per day diet and hCG injections offered a significant benefit to dieters, offering increased weight loss and a decrease in hunger.

In our study, we did not compare hCG and diet to diet alone, but our work shows the direction that such a study should take, as we utilize additional measures such as body composition (fat free mass, body fat, total body water, BMI) for all participants and lipid profiles and circulating progenitor cell levels for a group of the patients to assess outcome.

Our study provided further evidence of this linkage, with fat loss showing a strong correlation 
with changes in lipid profiles and increases in circulating progenitor cell numbers. For participants who represented weight loss and fat mass loss, the maximum reduction in lipids that have effect on overall cardiovascular health was $29 \%$ for cholesterol, $38 \%$ for LDL, $26 \%$ for cholesterol to HDL ratio and $35 \%$ for LDL to HDL ratio.

The average improvement of $\mathrm{CD} 34+$ cells in circulation during dieting program was $69 \% \pm 50 \%$.

In conclusion, the weight loss program analyzed in our study resulted in the improvement of the number of CD34+ cells in circulation and the decrease of the values of cardiovascular risk factors. According to our study, the circulating progenitor cell number can be improved by diet and weight loss.

\section{Acknowledgements}

This research was supported by Allan P. Markin.

\section{Conflict of Interest}

The authors have declared that no conflict of interest exists.

\section{References}

1. Ogden CL, Carroll MD, Curtin LR, McDowell MA, Tabak CJ, Flegal KM. Prevalence of overweight and obesity in the United States. 1999-2004. JAMA. 2006; 295: 1549-1555.

2. Schelbert KB. Comorbidities of obesity. Prim Care. 2009; 36: 271-285.

3. Balistreri CR, Caruso C, Candore G. The Role of Adipose Tissue and Adipokines in Obesity-Related Inflammatory Diseases. Mediators Inflamm. 2010; :802078.

4. Wozniak SE, Gee LL, Wachtel MS, Frezza EE. Adipose tissue: the new endocrine organ? A review article. Dig Dis Sci. 2009; 54:1847-1856

5. Yusuf S, Hawken S, Ounpuu S. Obesity and the risk of myocardial infarction in 27,000 participants from 52 countries: a case-control study. Lancet. 2005; 366: 1640 -1649.

6. Wolk R, Berger P, Lennon RJ, Brilakis ES, Somers VK. Body mass index: a risk factor for unstable angina and myocardial infarction in patients with angiographically confirmed coronary artery disease. Circulation. 2003; 108: $2206-2211$.

7. Adams KF, Schatzkin A, Harris TB, Kipnis V, Mouw T, Ballard-Barbash R, Hollenbeck A, Leitzmann MF. Overweight, obesity, and mortality in a large prospective cohort of persons 50 to 71 years old. N Engl J Med. 2006; 355: 763-778.

8. Calle EE, Thun MJ, Petrelli JM, Rodriguez C, Heath CWJr. Body mass index and mortality in a prospective cohort of US adults. N Engl J Med. 1999; 341: 1097-1105.

9. Allison DB, Fontaine KR, Manson JE, Stevens J, VanItallie TB. Annual deaths attributable to obesity in the United States. JAMA. 1999; 282: 1530-1538.

10. Eckel RH, Barouch WW, Ershow AG. Report of the National Heart, Lung, and Blood Institute-National Institute of Diabetes and Digestive and Kidney Diseases Working Group on the pathophysiology of obesity-associated cardiovascular disease. Circulation. 2002; 105: 2923-2928.

11. Grundy SM. Obesity, metabolic syndrome, and coronary atherosclerosis. Circulation. 2002; 105: 2696-2698.

12. Berg AH, Scherer PE. Adipose tissue, inflammation, and cardiovascular disease. Circ Res. 2005; 96: 939-949.
13. Takahashi T, Kalka C, Masuda H. Ischemia- and cytokine induced mobilization of bone marrow-derived endothelial progenitor cells for neovascularization. Nat Med. 1999; 5: 434-8.

14. Hirschi KK, Ingram DA, Yoder MC. Assessing identity, phenotype, and fate of endothelial progenitor cells. Arterioscler Thromb Vasc Biol. 2008; 28: 1584 -1595.

15. Schroeter MR, Leifheit M, Sudholt P. Leptin enhances the recruitment of endothelial progenitor cells into neointimal lesions after vascular injury by promoting integrin-mediated adhesion. Circ Res. 2008; 103: 536-544.

16. Werner N, Junk S, Laufs U. Intravenous transfusion of endothelial progenitor cells reduces neointima formation after vascular injury. Circ Res. 2003; 93: e17-24.

17. MacEneaney OJ, Kushner EJ, Van Guilder GP, Greiner JJ, Brian L Stauffer BL, DeSouza CA. Endothelial progenitor cell number and colony forming capacity in overweight and obese adults. Int J Obes (Lond). 2009; 33: 219-225.

18. Muller-Ehmsen J, Braun D, Schneider T, Roman Pfister R, Worm N, Wielckens K, Scheid C, Frommolt P, Flesch M. Decreased number of circulating progenitor cells in obesity: beneficial effects of weight reduction. European Heart Journal. 2008; 29: 1560-1568.

19. Van Guilder GP, Hoetzer GL, Dengel DR, Stauffer BL, DeSouza CA. Impaired endothelium-dependent vasodilation in normotensive and normoglycemic obese adult humans. J Cardiovasc Pharmacol. 2006; 47: 310-313.

20. Van Guilder GP, Hoetzer GL, Smith DT, Irmiger HM, Greiner JJ, Stauffer BL, DeSouza CA. Endothelial t-PA release is impaired in overweight and obese adults but can be improved with regular aerobic exercise. Am J Physiol Endocrinol Metab. 2005; 289: E807-E813.

21. Dzau VJ, Gnecchi M, Pachori AS, Morello F, Melo LG. Therapeutic potential of endothelial progenitor cells in cardiovascular diseases. Hypertension. 2005; 46: 7-18.

22. Heida N-M, Müller JP, Cheng IF, Leifheit-Nestler M, Faustin V, Riggert J, Hasenfuss G, Konstantinides S, Schäfer K. Effects of Obesity and Weight Loss on the Functional Properties of Early Outgrowth Endothelial Progenitor Cells. Journal of the American College of Cardiology. 2010; 55: 357-367.

23. Simeons ATW. The action of chorionic gonadotropin in the obese. Lancet 1954;:946-947.

24. Simeons ATW. Chorionic gonadotropin in the obese. Lancet 1962;: 47-48.

25. Rabe T, Richter S, Kiesel L, Runnebaum B. Risk-benefit analysis of a hCG-500 kcal reducing diet (cura romana) in females. Geburtshilfe Frauenheilkd. 1987; 47: 297-307.

26. Lijesen GK, Theeuwen I, Assendelft WJ, Van Der Wal G. The effect of human chorionic gonadotropin (HCG) in the treatment of obesity by means of the Simeons therapy: a criteria-based meta-analysis. Br J Clin Pharmacol. 1995; 40: 237-243.

27. Sutherland DR, Anderson L, Keeney M, Nayar R, Chin-Yee I. The ISHAGE guidelines for CD34+ cell determination by Flow cytometry. Journal of hematotherapy. 1996; 5: 213-226.

28. Asahara T, Murohara T, Sullivan A, Silver M, van der Zee R, Li $\mathrm{T}$. Isolation of putative progenitor endothelial cells for angiogenesis. Science. 1997; 275: 964-967.

29. Timmermans F, Van Hauwermeiren F, De Smedt M, Raedt R, Plasschaert F, De Buyzere ML, Gillebert TC, Plum J, Vandekerckhove B. Endothelial outgrowth cells are not derived from CD133+ cells or CD45+ hematopoietic precursors. Arterioscler Thromb Vasc Biol. 2007;27:1572-1579

30. Reaven, G. M. Role of insulin resistance in human disease (syndrome X): an expanded definition. Annu Rev Med. 1993; 44: $121-131$

31. Steinberg, H. O, Chaker, H, Leaming, R, Johnson, A, Brechtel, G, Baron, A. Obesity/insulin resistance is associated with endothelial dysfunction. J Clin Invest. 1996; 97: 2601-2610. 
32. Arcaro G, Zamboni M, Rossi L, Turcato E, Covi G, Armellini F, Bosello O, Lechi A. Body fat distribution predicts the degree of endothelial dysfunction in uncomplicated obesity. Int J Obes Relat Metab Disord. 1999; 23: 936-942.

33. Caballero EA. Endothelial Dysfunction in Obesity and Insulin Resistance: A Road to Diabetes and Heart Disease. Obesity Research. 2003; 11: 1278-1289.

34. Brown CD, Higgins M, Donato KA, Rohde FC, Garrison R, Obarzanek E, Ernst ND, Horan M. Body mass index and the prevalence of hypertension and dyslipidemia. Obes Res. 2000; 8: 605-619.

35. Lundman P, Eriksson MJ, Silveira A, Hansson LO, Pernow J, Ericsson CG, Hamsten A, Tornvall P. Relation of hypertriglyceridemia to plasma concentrations of biochemical markers of inflammation and endothelial activation (C-reactive protein, interleukin -6 , soluble adhesion molecules, von Willebrand factor, and endothelin -1). Am J Cardiol. 2003; 91: 1128-1131.

36. Ferreira AC, Peter AA, Mendez AJ, Jimenez JJ, Mauro LM, Chirinos JA, Ghany R, Virani S, Garcia S, Horstman LL, Purow J, Jy W, Ahn YS, de Marchena E. Postprandial Hypertriglyceridemia Increases Circulating Levels of Endothelial Cell Microparticles. Circulation. 2004; 110: 3599 - 3603.

37. Libby P. Vascular biology of athrosclerosis: overview and state of art. Am J Cardiol. 2003; 91: 3A-6A.

38. Ross R. Cell biology of atherosclerosis. Annu Rev Physiol. 1995; 57: 791-804.

39. Shmilovich H, Deutsch V, Roth A, Miller H, Keren G, Georg J. Circulating endothelial progenitor cells in patients with cardiac syndrome X. Heart. 2007; 93: 1071 - 1076.

40. Werner N, Kosiol S, Schiegl T, Ahlers P, Walenta K, Link A, Böhm M, Nickenig G. Circulating Endothelial Progenitor Cells and Cardiovascular Outcomes. N Engl J Med. 2005; 353: 999-1007.

41. Fadini GP, de Kreutzenberg SV, Coracina A, Baesso I, Agostini C, Tiengo A, Avogaro A. Circulating CD34+ cells, metabolic syndrome, and cardiovascular risk. Eur Heart J. 2006; 27: 2247-2255.

42. Hill JM, Zalos G, Halcox JP, Schenke WH, Waclawiw MA, Quyyumi AA, Finkel T. Circulating endothelial progenitor cells, vascular function, and cardiovascular risk. New England Journal of Medicine. 2003; 348: 593-600.

43. Vasa M, Fichtlscherer S, Aicher A, Adler K, Urbich C, Martin H, Zeiher AM, Dimmeler S. Number and migratory activity of circulating endothelial progenitor cells inversely correlate with risk factors for coronary artery disease. Circ Res. 2001; 89: E1-7.

44. Young RL, Fuchs RJ, Woltjen MJ. Chorionic gonadotropin in weight control. A double-blind crossover study. JAMA. 1976; 236:2495-2497.

45. Greenway FL, Bray GA. Human chorionic gonadotropin (HCG) in the treatment of obesity: a critical assessment of the Simeons method. West J Med. 1977; 127: 461-463.

46. Asher WL, Harper HW. Effect of human chorionic gonadotrophin on weight loss, hunger and feeling of well-being. Am J Clin Nutr. 1973; 26: 211-218. 